\title{
Design and Simulation of Micromachined Gyroscope Based on Finite Element Method
}

\author{
Nguyen Van Thang ${ }^{1, *}$, Tran Duc Tan ${ }^{2}$, Chu Duc Trinh ${ }^{2}$ \\ ${ }^{1}$ Broadcasting College I - Voice of Vietnam, Phu Ly, Ha Nam, Vietnam \\ ${ }^{2}$ VNU University of Engineering and Technology, Hanoi, Vietnam \\ Received 22 December 2016 \\ Revised 14 March 2017; Accepted 22 March 2017
}

\begin{abstract}
This paper presents a design, simulation and analysis of a vibratory micromachining gyroscope. The gyroscope structure is based on the driving and sensing proof-mass configuration. The gyroscope dimensions are $1644 \mu \mathrm{m}$ wide, $1754 \mu \mathrm{m}$ long, 30 $\mu \mathrm{m}$ thickness. The suspended spring consists of two silicon cantilevers of driving-mode and sensing-mode stiffness are $400 \mathrm{~N} / \mathrm{m}$ and $165 \mathrm{~N} / \mathrm{m}$, respectively. Mass of driving proof-mass (including of $0.9408 \times 10 \mathrm{E}-11 \mathrm{~kg}$ sensing proof-mass) is $0.5452 \times 10 \mathrm{E}-7 \mathrm{~kg}$. The simulated resonance frequency is $13324 \mathrm{~Hz}$. The output signals are calculated based on the simulated vibration results. The structure is investigated with several input angular signals. The sensitivity of proposed structure is $100 \mathrm{mV} / \mathrm{rad} / \mathrm{s}$ when $\omega$ changes from 0 to $1.6 \mathrm{rad} / \mathrm{s}$.
\end{abstract}

Keywords: Gyroscope, Tuning Fork Gyroscope, Comsol Multiphysics and Gyroscope.

\section{Introduction}

In recent years, gyroscopes in general and micromachined gyroscopes in particular have been very popularly used [1], [2]. A specific analysis of the cause of vibration-induced error is implemented to understand the vibration effects on ideal tuning fork gyroscopes (TFGs) [3]. This research presents the major causes of error that arise from: capacitive nonlinearity at the sense electrode, asymmetric electrostatic forces along the drive direction at the drive electrodes and asymmetric electrostatic forces along sense direction at the drive electrodes. In some applications, operation and performance of gyroscopes are affected by a lot of changing environmental conditions such as temperature, pressure, or ambient vibrations [4], [5]. The stiffness of the springs and sensors to these external influences during operation is critical for adequate performance [6]. A new MEMS gyroscope design can improve performance of angle measurement shown in [7] while the other is developed either to upgrade the performance or to reduce the cost [8]. Besides that, there are also optimal MEMS gyroscope structures: micromachined disk or ring designed to have the better precision [9], [10]. Reference [11] utilizes symmetrically decoupled tines with sense-mode coupling structures and drive-

\footnotetext{
Corresponding author. Tel.: 84- 982865355 .

Email: nguyenbathangvov@gmail.com

https//doi.org/ 10.25073/2588-1124/vnumap.4215
} 
mode synchronization. The levered drive-mode mechanism structurally forces the anti-parallel, antiphase drive-mode motion and eliminates the lower frequency spurious mode presented in conventional TFGs. The linearly coupled, momentum and torque balanced anti-phase sense-mode reduces dissipation of energy via the substrate yielding ultra-high quality factors. The study [12] indicated that the most important problem in the quadruple-mass design is to be expected to enable rate integrating mode of operation due to its unique combination of isotropy and low energy dissipation of both damping and the resonant frequency.

Above studies were successfully implemented based on design, simulation, and analysis processes of a vibratory micromachining gyroscope. In the most of studies related to gyroscopes, simulation and analysis processes before fabrication is very important because it help us to shorten the time and reduce test expenditure. In this paper, we propose a new structure of a MEMS - based vibratory micromachining gyroscope which exploits the electronics and mechanical cosimulation using finite element method.

\section{Structure and operating principle of gyroscope}

Figure 1 shows a 2-DOF vibratory rate gyroscope. In fact, the gyroscope is included a substrate, a proof-mass and anchored flexures. The proof-mass is suspended above the substrate and supported by anchored flexures which play the role of a flexible suspension between the substrate and the proofmass. This kind of structure allows the proof-mass free to oscillate in two orthogonal directions: the driving direction $(X-$ axis $)$ and sensing direction ( $Y$ - axis). In the driving mode, the suspension system allows the proof-mass to oscillate in $X$ - axis. The proof-mass is driven into resonance in $X$-axis by an external sinusoidal voltage at the resonant frequency of the driving mode. Accelerometer of the sensing mode is formed by the proof-mass. The suspension system allows the proof-mass to oscillate in $Y$ - axis. When the gyroscope is rotated an angular rate $\omega$, a sinusoidal Coriolis force at the frequency of driving mode oscillation is induced in the sensing direction. The Coriolis force excites the sensing mode accelerometer, causing the proof-mass to respond in the sensing direction [6].

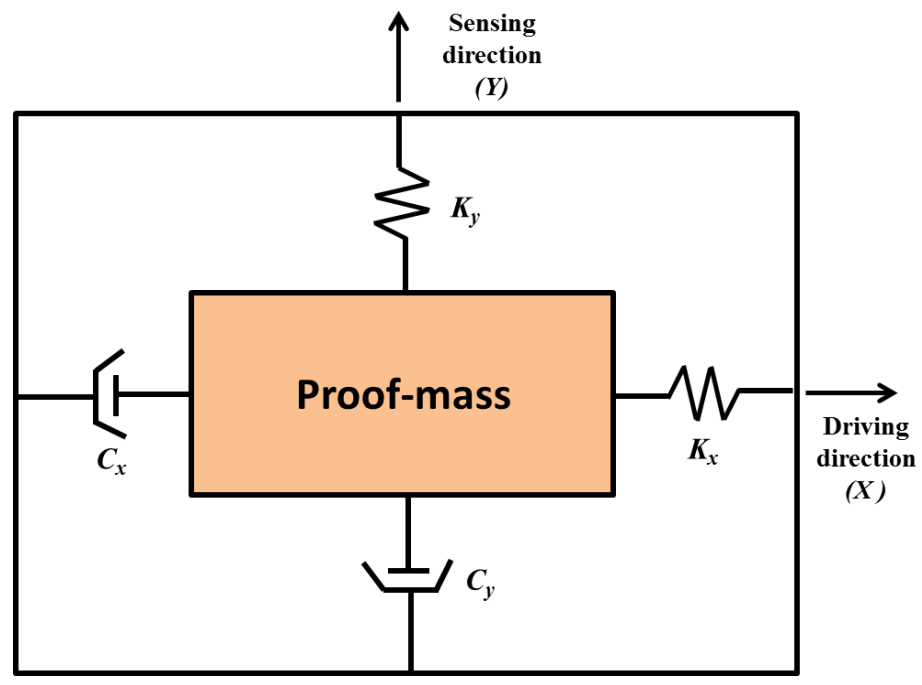

Fig. 1. A 2-DOF vibratory rate gyroscope. 


\section{Structure design}

In this study, the whole design and simulation processes are implemented based on a finite element method via the software COMSOL MULTIPHYSICS (COMSOL Inc.). This software is used in a lot of application areas such as Microelectromechanical systems (MEMS); Structural mechanics; heat transfer; Microfluidics etc. Physics interfaces in COMSOL allow to perform various types of studies including: stationary and time-dependent (transient) studies; linear and nonlinear studies; eigenfrequency, modal, and frequency response studies [13], [14].

This software is integrated kinds of material and their parameters. Materials utilized in this work are Polysilicon and Air. Where, the structure is designed by Polysilicon material and assumed to be immersed in Air. Some material contents of Polysilicon and Air is shown in Table 1 and Table 2.

Table 1. Material contents of Polysilicon

\begin{tabular}{llll}
\hline Property & Name & Value & Unit \\
\hline Density & rho & $2230\left[\mathrm{~kg} / \mathrm{m}^{3}\right]$ & $\mathrm{kg} / \mathrm{m}^{3}$ \\
Poisson's ratio & nu & 0.22 & 1 \\
Young's modulus & $\mathrm{E}$ & $169 \mathrm{e} 9[\mathrm{~Pa}]$ & $\mathrm{Pa}$ \\
Heat capacity at constant pressure & $\mathrm{Cp}$ & $678[\mathrm{~J} /(\mathrm{kg} \cdot \mathrm{K})]$ & $\mathrm{J} /(\mathrm{kg} \cdot \mathrm{K})$ \\
Relative permittivity & Epsilonr & 4.5 & 1 \\
Thermal conductivity & $\mathrm{k}$ & $\mathrm{k}(\mathrm{T})[\mathrm{W} /(\mathrm{m} . \mathrm{K})$ & $\mathrm{W} /(\mathrm{m} . \mathrm{K})$ \\
Reference resistivity & rho0 & $2 \mathrm{e}-5$ & $\Omega . \mathrm{m}$ \\
Resistivity temperature coefficient & alpha & $1.25 \mathrm{e}-3$ & $1 / \mathrm{K}$ \\
Reference temperature & Tref & $298.15[\mathrm{~K}]$ & $\mathrm{K}$ \\
\hline
\end{tabular}

Table 2. Material contents of Air

\begin{tabular}{llll}
\hline Property & Name & Value & Unit \\
\hline Relative permeability & mur & 1 & 1 \\
Relative permittivity & epsilonr & 10 & 1 \\
Ratio of specific heats & gamma & 1.4 & 1 \\
Electrical conductivity & sigma & $0[\mathrm{~S} / \mathrm{m}]$ & $\mathrm{S} / \mathrm{m}$ \\
Heat capacity of at constant pressure & $\mathrm{Cp}$ & $\mathrm{Cp}(\mathrm{T}[1 / \mathrm{K}][\mathrm{J} /(\mathrm{kg} . \mathrm{K})]$ & $\mathrm{J} /(\mathrm{kg} . \mathrm{K})$ \\
Density & $\mathrm{rho}$ & $\operatorname{rho}(\mathrm{pA}[1 / \mathrm{Pa}], \mathrm{T}[1 / \mathrm{K}])\left[\mathrm{kg} / \mathrm{m}^{3}\right]$ & $\mathrm{kg} / \mathrm{m}^{3}$ \\
Thermal conductivity & $\mathrm{k}$ & $\mathrm{k}(\mathrm{T}[1 / \mathrm{K}])\left[\mathrm{W} /\left(\mathrm{m}^{*} \mathrm{~K}\right)\right]$ & $\mathrm{W} /(\mathrm{m} \cdot \mathrm{K})$ \\
Speed of sound & $\mathrm{c}$ & $\mathrm{cs}(\mathrm{T}[1 / \mathrm{K}])[\mathrm{m} / \mathrm{s}]$ & $\mathrm{m} / \mathrm{s}$ \\
Refractive Index & $\mathrm{n}$ & 1 & 1 \\
Refractive Index, Imaginary part & $\mathrm{ki}$ & 0 & 1 \\
\hline
\end{tabular}

Figure 2 shows 2-DOF design of a micromachined gyroscope operating based on capacitance effects. The drive frame is suspended on four $X$-axis springs. Capacitive actuator drives the frame to oscillate on drive resonant frequency. The sense mass is hanged on the driving frame thanks to two ellipse shape $Y$-axis springs. In case of having excited drive signals, the drive proof-mass oscillates along the $X$-axis and the sense proof-mass oscillates along the $Y$-axis when gyroscope is effected by $\omega$ angular rate.

Mass of driving proof-mass (including of $0.9408 \times 10 \mathrm{e}-11 \mathrm{~kg}$ sensing proof-mass) is $0.5452 \times 10^{-7}$ $\mathrm{kg}$. The stiffness of driving spring is $K_{d}=400 \mathrm{~N} / \mathrm{m}$ (including eights springs (1)) and the stiffness of sensing spring is $K_{s}=165 \mathrm{~N} / \mathrm{m}$ (including two ellipse shape springs (2)). The designed parameters of the proposed gyroscope are shown in Table 3. 


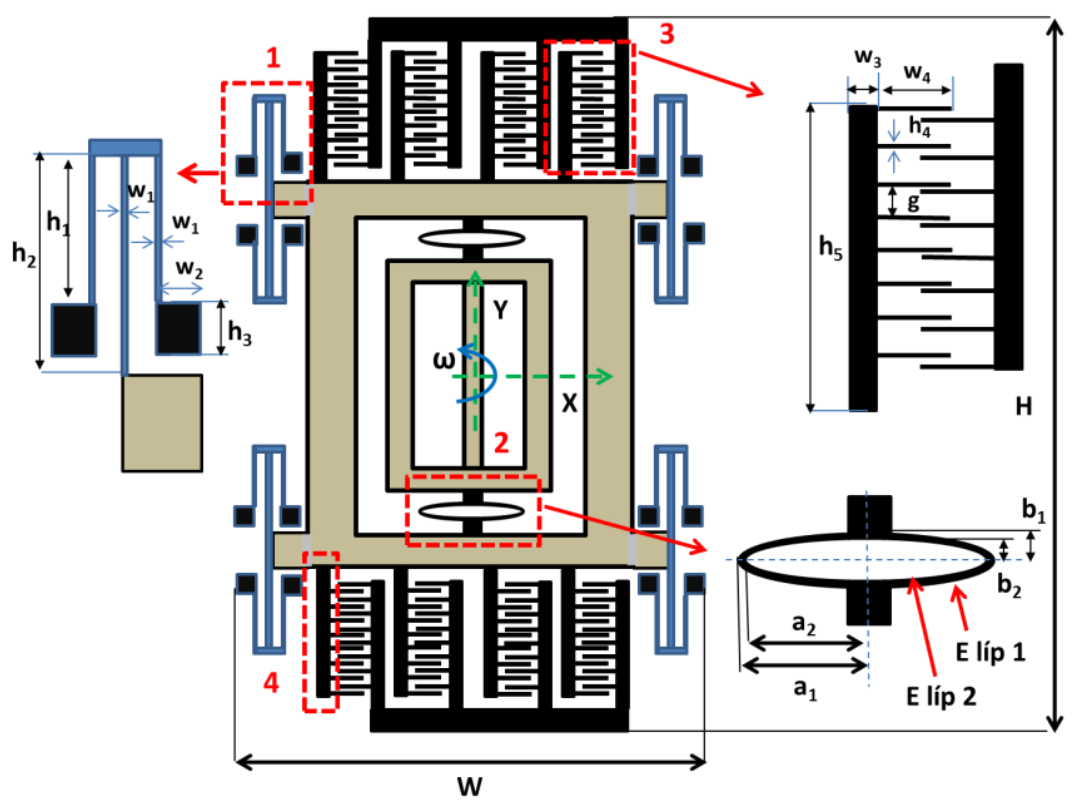

Fig. 2 The proposed Gyroscope: Drive springs (1), Sense springs (2), Drive capacitor pairs (3), Drive comb frame (4)

Table 3. The proposed gyroscope structure parameters

\begin{tabular}{ll}
\hline Parameter & Size/Quantity/Value \\
\hline Real gyroscope long/height $(H)$ & $1754 \mu \mathrm{m}$ \\
Real gyroscope width $(W)$ & $1644 \mu \mathrm{m}$ \\
Device thickness $(t)$ & $30 \mu \mathrm{m}$ \\
Outer frame height $\left(h_{\mathrm{dpm}}\right)$ & $1200 \mu \mathrm{m}$ \\
Outer frame width $\left(w_{\mathrm{dpm}}\right)$ & $1300 \mu \mathrm{m}$ \\
Inner frame height $\left(h_{\mathrm{spm}}\right)$ & $840 \mu \mathrm{m}$ \\
Inner frame width $\left(w_{\mathrm{spm}}\right)$ & $940 \mu \mathrm{m}$ \\
Drive sub-suspension beam height $\left(h_{1}\right)$ & $190 \mu \mathrm{m}$ \\
Drive main suspension beam height $\left(h_{2}\right)$ & $260 \mu \mathrm{m}$ \\
Drive suspension beam width $\left(w_{1}\right)$ & $6 \mu \mathrm{m}$ \\
Anchor size $\left(w_{2} \times h_{3}\right)$ & $40 \mu \mathrm{m} \times 40 \mu \mathrm{m}$ \\
Number of drive comb frames & 8 \\
Drive comb frame height $\left(h_{5}\right)$ & $200 \mu \mathrm{m}$ \\
Drive comb frame width $\left(w_{3}\right)$ & $25 \mu \mathrm{m}$ \\
Number of comb fingers in a drive comb frame & 15 \\
Drive comb finger size $\left(w_{4} \times h_{4}\right)$ & $50 \mu \mathrm{m} \times 3 \mu \mathrm{m}$ \\
Gap between two drive comb finger & $2.5 \mu \mathrm{m}$ \\
Gap between two comb fingers in the same frame $(g)$ & $8 \mu \mathrm{m}$ \\
Drive finger overlap length $\left(l_{d f o}\right)$ & $10 \mu \mathrm{m}$ \\
Ellipse 1 sense suspension beam size $\left(a_{1} \times b_{1}\right)$ & $150 \mu \mathrm{m} \times 20 \mu \mathrm{m}$ \\
Ellipse 2 sense suspension beam size $\left(a_{2} \times b_{2}\right)$ & $146 \mu \mathrm{m} \times 16 \mu \mathrm{m}$ \\
Drive mass $\left(m_{d}\right)$ & $0.5452 \times 10^{-7} \mathrm{Kg}$ \\
Sense mass $\left(m_{\mathrm{s}}\right)$ & $0.9408 \times 10^{-11} \mathrm{Kg}$ \\
Driving mode stiffness $\left(K_{\mathrm{d}}\right)$ & $400 \mathrm{~N} / \mathrm{m}$ \\
Sensing mode stiffness $\left(K_{\mathrm{s}}\right)$ & $165 \mathrm{~N} / \mathrm{m}$ \\
\hline
\end{tabular}




\section{Simulation results}

\subsection{Mesh settings}

After designing structure, the next work is Mesh settings. In this study, we use Sequency type: Physics-controlled mesh and Element size: Normal. Gyroscope after meshing is shown in Fig. 3.

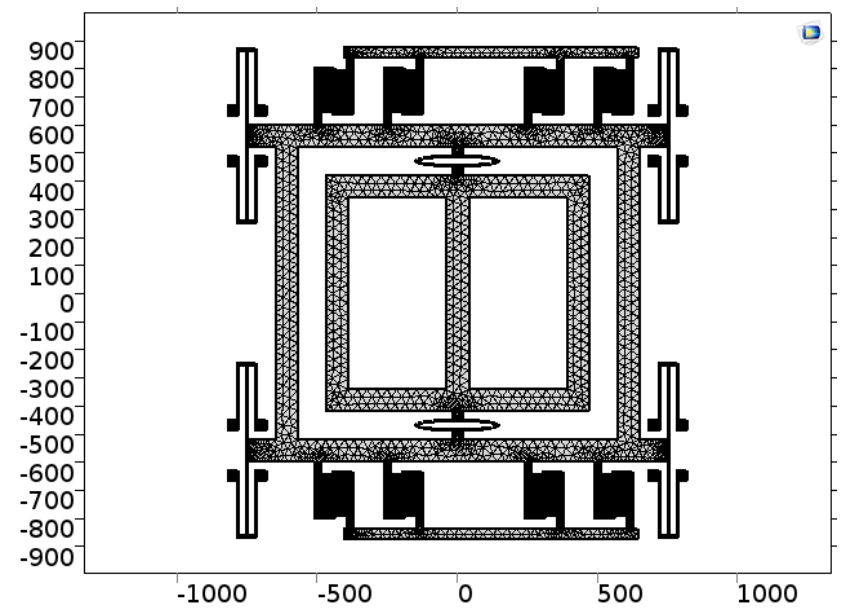

Fig. 3. Mesh image of gyroscope (unit: $\mu \mathrm{m}$ ).

\subsection{Finding Eigenfrequencies}

The next step of mesh settings is to simulate to find out resonance frequencies in drive direction and in sense direction. The design needs to obtain approximation about the resonance frequencies in two directions. So, in the implementation process the design may be corrected many times before having the desired frequencies. Its main purpose is to have high quality and maximum displacements of drive proof-mass and sense proof-mass.

Oscillation modes of proposed gyroscope are found out in Comsol Multiphysics software: Study/Study steps/Eigenfrequency/Eigenfrequency.

Some eigenfrequency analysis results of the gyroscope achieved by COMSOL are shown in Fig. 4. In these Figures, the unit of $x$ and $y$-axes is $\mu m$. Eigenfrequencies are shown in Table 4.

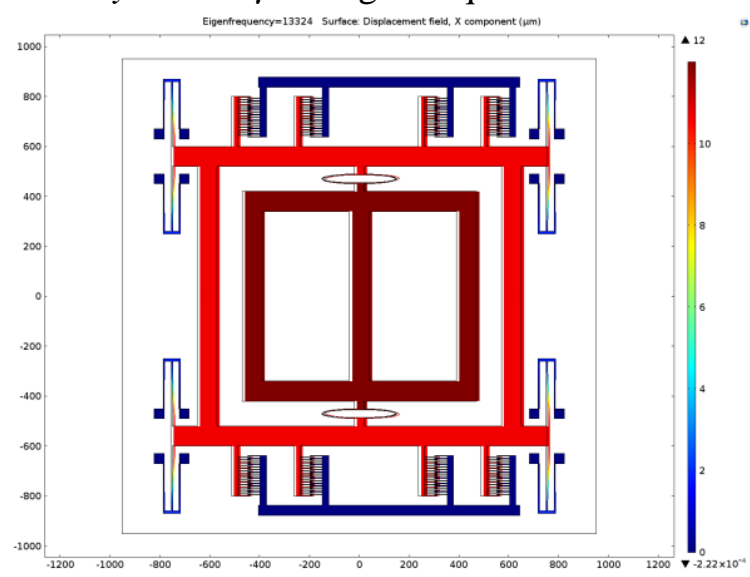

a) Mode 1 (Driving Mode). 


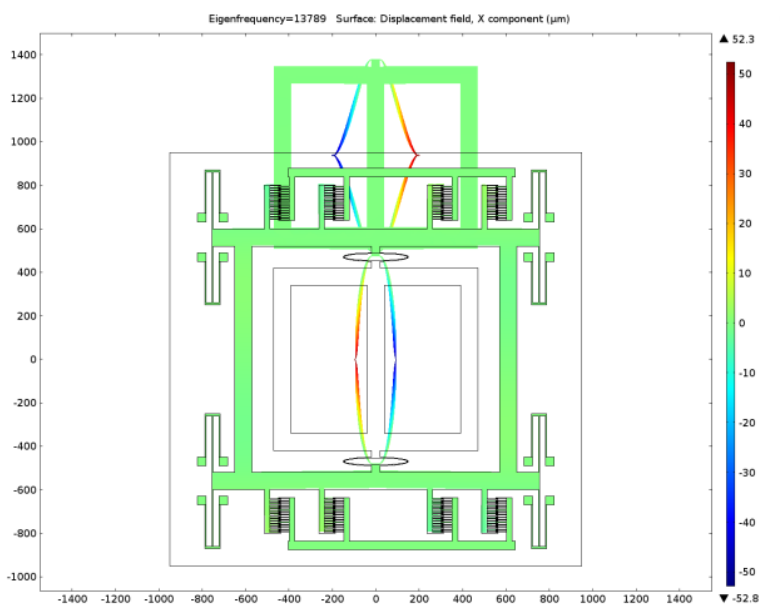

b) Mode 2 (Sensing Mode).

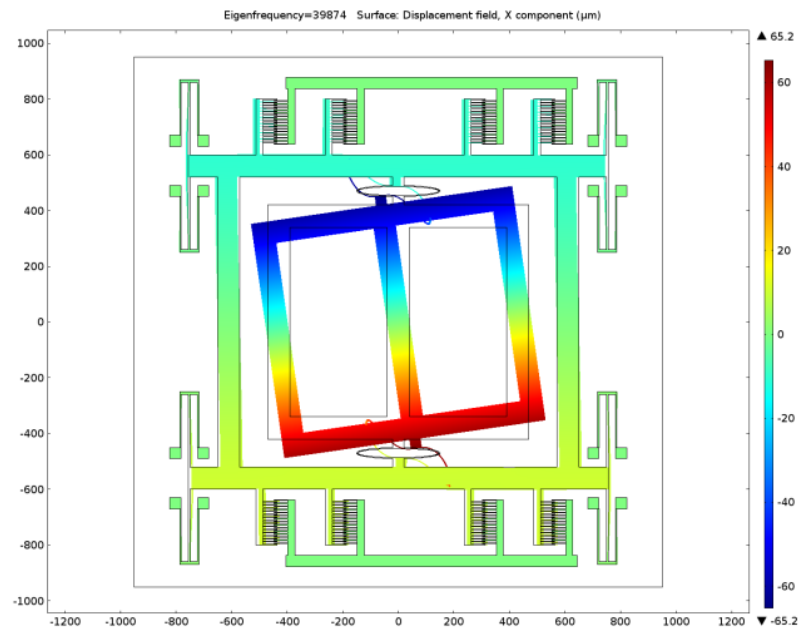

c) Mode 3 .

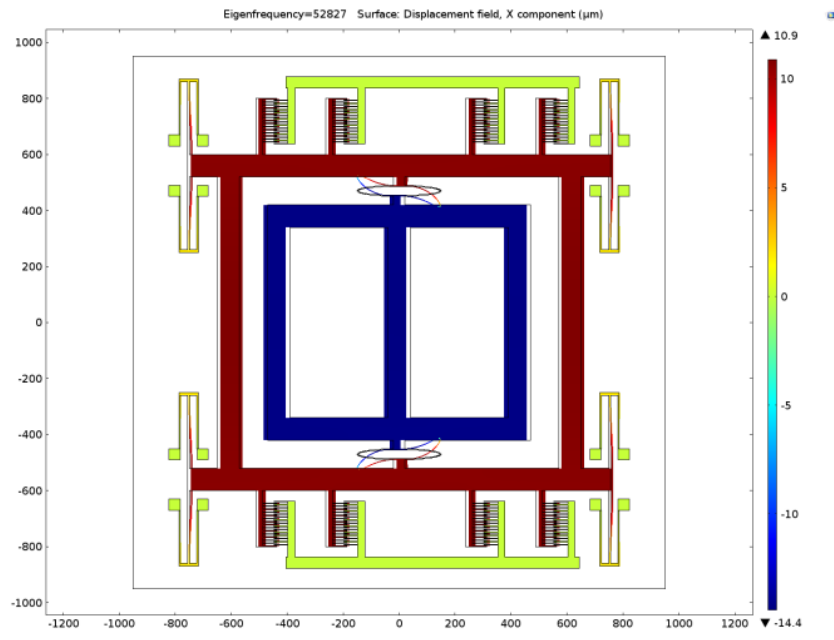

d) Mode 4. 


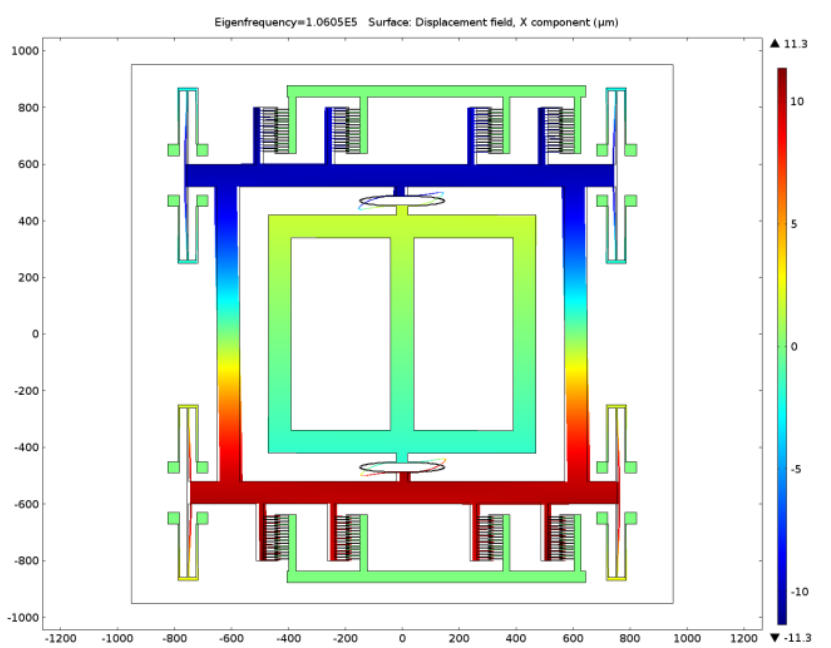

e) Mode 5 .

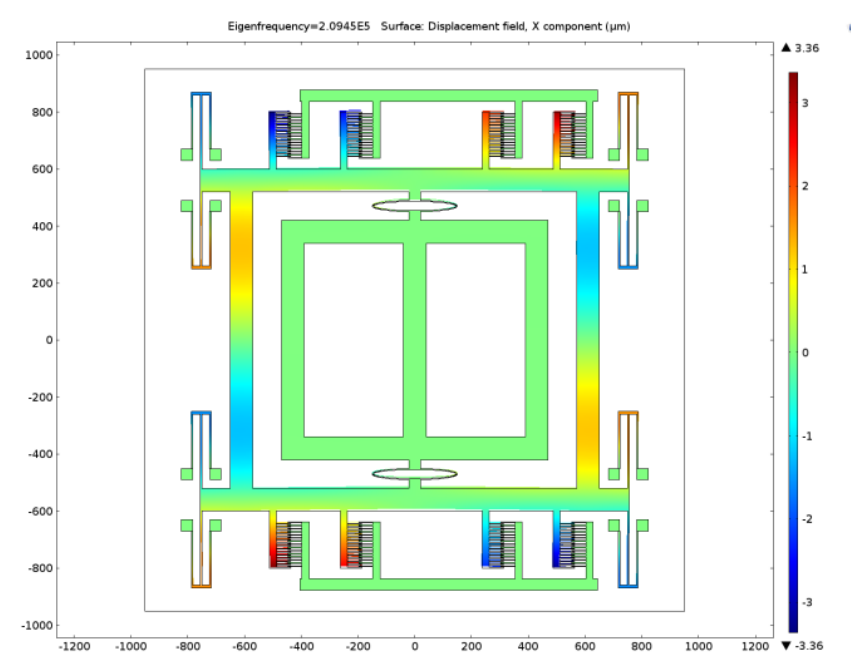

f) Mode 6 .

Fig 4. The Eigenfrequency analysis results of the proposed Gyroscope

Table 4. Six oscillation modes of proposed gyroscope

\begin{tabular}{l|l}
\hline Oscillation modes & Frequency $(\mathrm{Hz})$ \\
\hline First (driving mode) & 13324 \\
Second (sensing mode) & 13789 \\
Third & 39874 \\
Fourth & 52827 \\
Fifth & 106050 \\
Sixth & 209450 \\
\hline
\end{tabular}

\subsection{Stiffness of spring and suspension system}

The stiffness of spring is computed basing on the formula:

$$
F=k * x
$$


where: $F$ is force, which applies to a spring; $k$ is called the spring constant, which measures how stiff and strong the spring is and $x$ is the distance the spring is stretched or compressed away from its equilibrium or rest position.

The position of applying force and displacement of driving spring, driving proof-mass and sensing proof-mass are pointed out in Fig. 5, Fig. 6, Fig. 7, respectively. The stiffness of driving mode and sensing mode are listed in the Table 3.

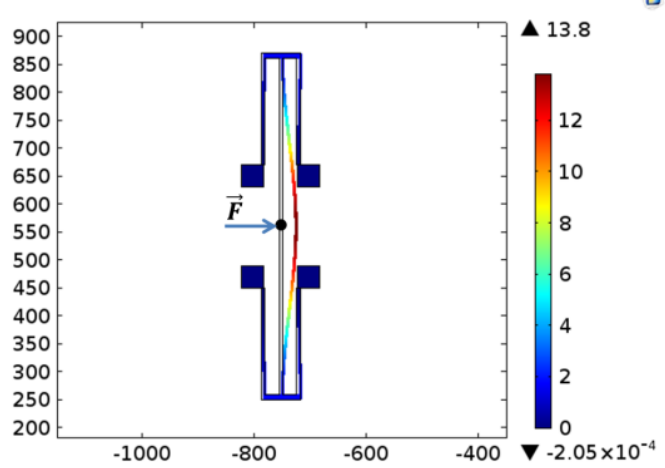

Fig. 5. The position of applying force and displacement of driving spring (unit: $\mu m$ )

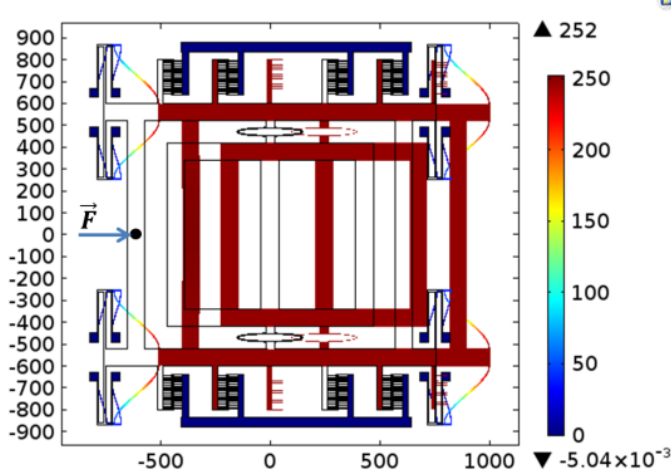

Fig. 6. The position of applying force and displacement of driving proof-mass (unit: $\mu \mathrm{m}$ )

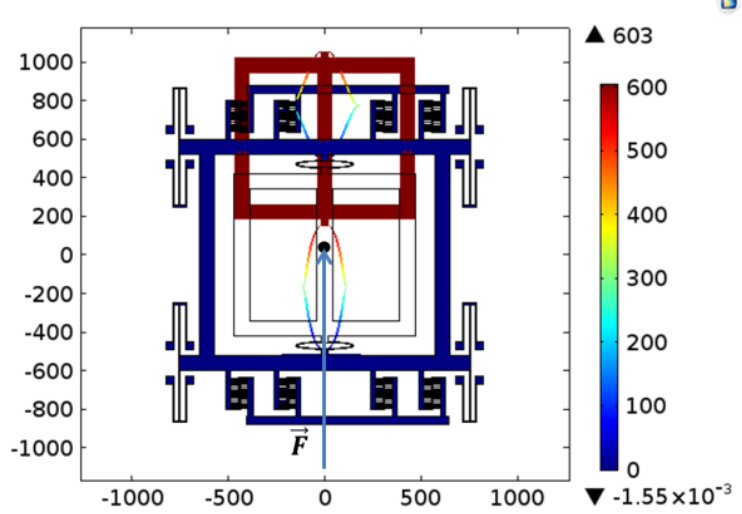

Fig. 7. The position of applying force and displacement of sensing proof-mass (unit: $\mu \mathrm{m}$ ). 


\subsection{Output displacement}

In this paper, the drive oscillation is excited by applying a voltage $V_{\text {in }}$ to drive capacitor pairs:

$$
V_{i n}=V_{D C}+V_{A C}=10+10 \sin (2 \pi f t)
$$

where $f$ is the resonance frequency in driving mode.

Figure 8 points out the mechanical displaced magnitude and signal shape of driving proof-mass in period of $3.3 \times 10^{-3} \mathrm{~s}$.

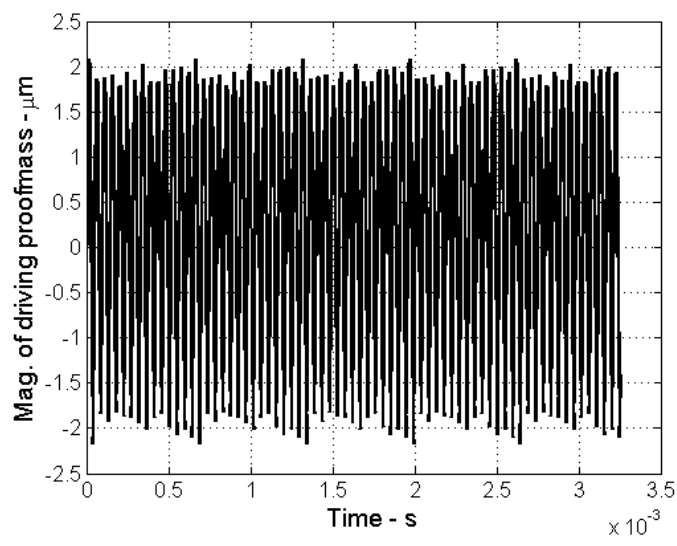

Fig. 8. The mechanical displacement of driving proof-mass.

When the gyroscope is oscillating and is rotated by an angular rate $\omega_{1}$ shown in equation 3 (see Fig. 9a), the sensing proof-mass is oscillated in sensing-axis (see Fig. 9b). This oscillation is called modulation signal (amplitude modulation). To obtain $\omega_{1}$ from modulation signal, it needs to implement a demodulation process (see Fig. 9c).

$\omega_{1}=1+0.6 \sin \left(8 e 3^{*}\right.$ Time $)$

where Time $=3.3 \times 10^{-3} \mathrm{~s}$.

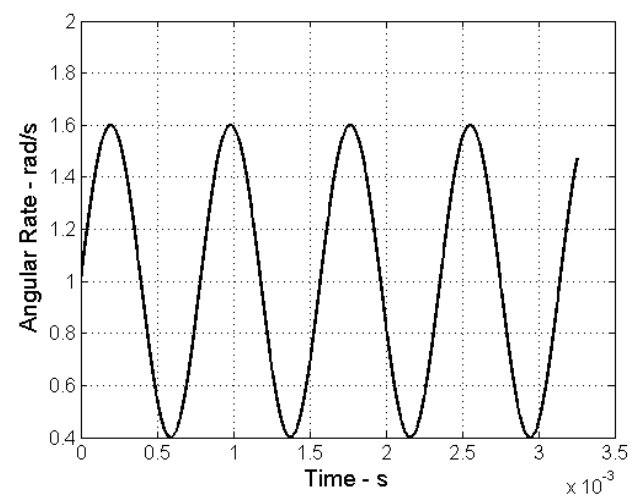

(a) 


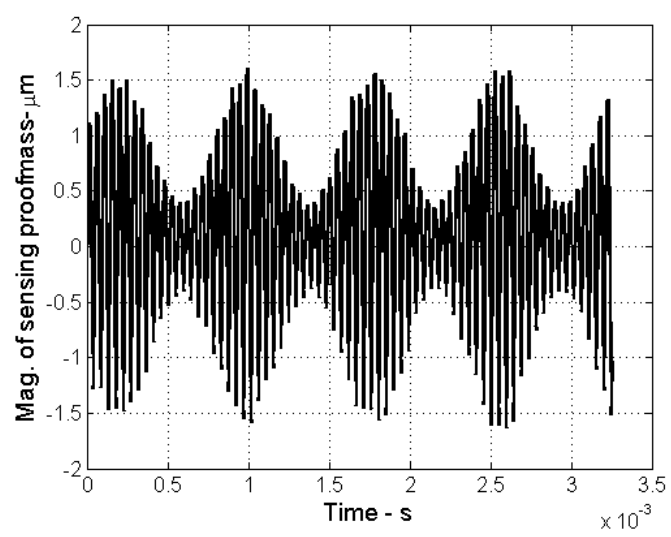

(b)

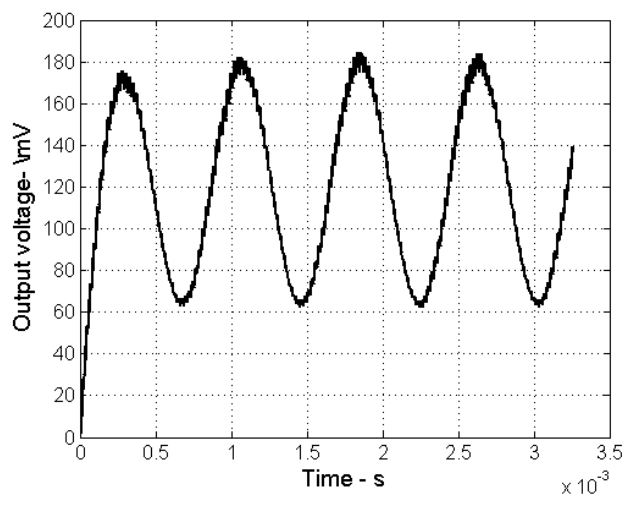

(c)

Fig. 9. Simulation results with $\omega_{1}$. (a) Sine angular rate as an input signal applied to the gyroscope; (b) Sensing output signal (modulation); and (c) output signal (after demodulation)

In case of changing angular rate $\omega_{1}$ into $\omega_{2}$ and $\omega_{3}$ (described in equation 4 and 5), the corresponding modulation and demodulation signals were shown in Fig. 10 and Fig. 11.

$$
\begin{aligned}
& \omega_{2}=1+2 \sin (8 e 3 * \text { Time }) \\
& \omega_{3}=1+0.6 \sin (5 e 3 * \text { Time })
\end{aligned}
$$

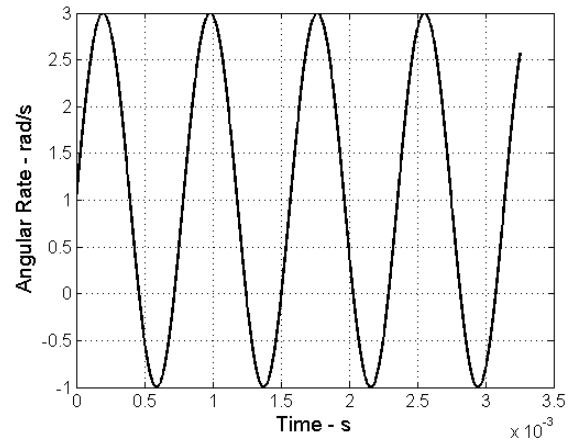

(a)

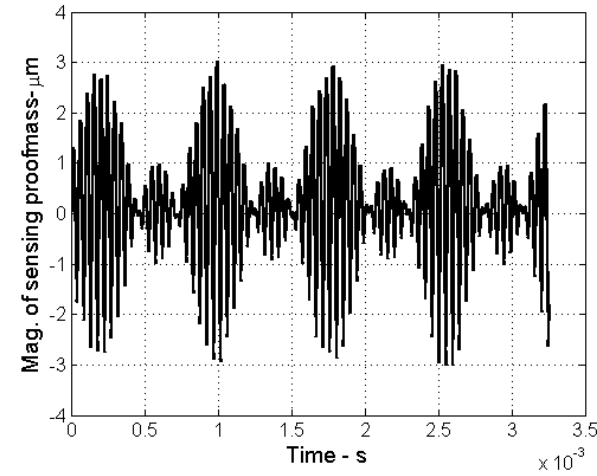

(b)

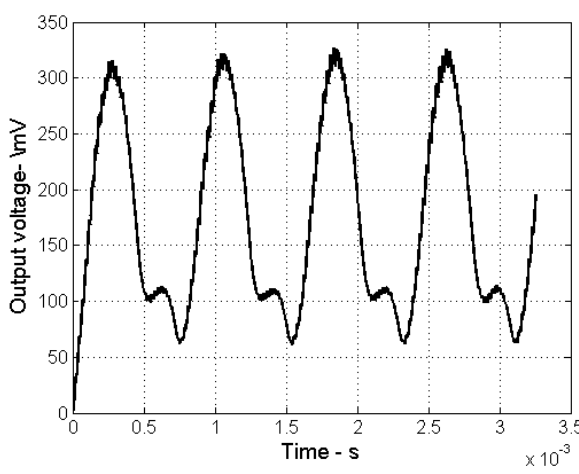

(c)

Fig. 10. Simulation results with $\omega_{2}$. (a) Sine angular rate as an input signal applied to the gyroscope; (b) Sensing output signal (modulation); and (c) output signal (after demodulation). 


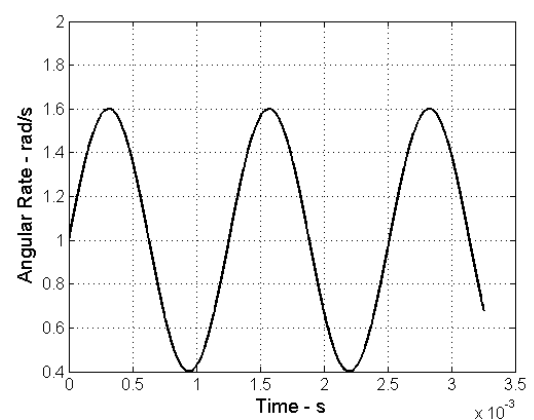

(a)

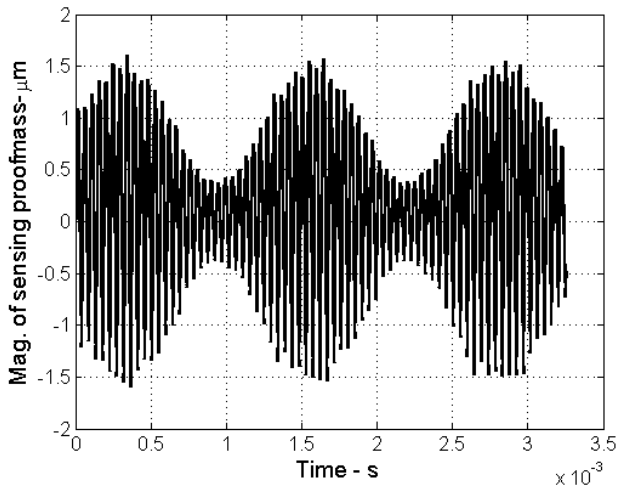

(b)

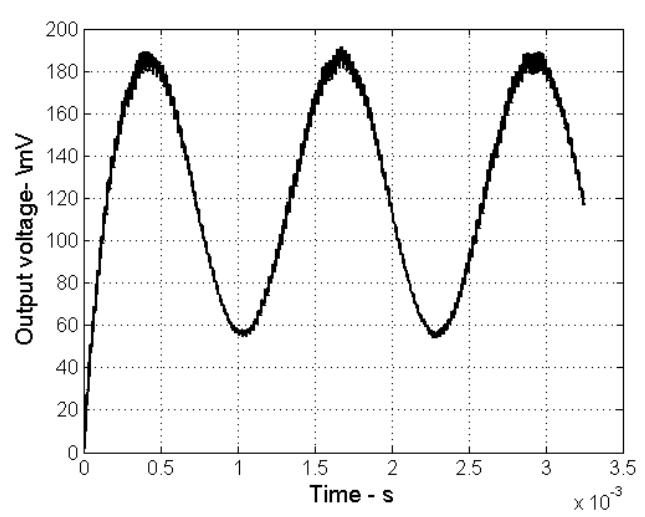

(c)

Fig. 11. Simulation results with $\omega_{3}$. (a) Sine angular rate as an input signal applied to the gyroscope; (b) Sensing output signal (modulation); and (c) output signal (after demodulation)

Based on results in Fig. 9b, Fig. 10b and Fig. 11b, we can see that the modulation signals are changed according to input angular rate $\omega$. In case of normal modulations (modulation factor $\leq 1.0$ ), the recovered signals (demodulation signals) are quite like original signals $\omega$ (see Fig. 9c and Fig. 11c). When implementing the excessive amplitude modulation (modulation factor $>1.0$ ), the demodulated signal is distorted (see Fig. 10c).

Figure 12 shows the relationship between input angular rate $\omega(\mathrm{rad} / \mathrm{s})$ and output voltage $(\mathrm{mV})$. This is linearly relationship and the sensitivity is $100 \mathrm{mV} / \mathrm{rad} / \mathrm{s}$ when $\omega$ changes from 0 to $1.6 \mathrm{rad} / \mathrm{s}$.

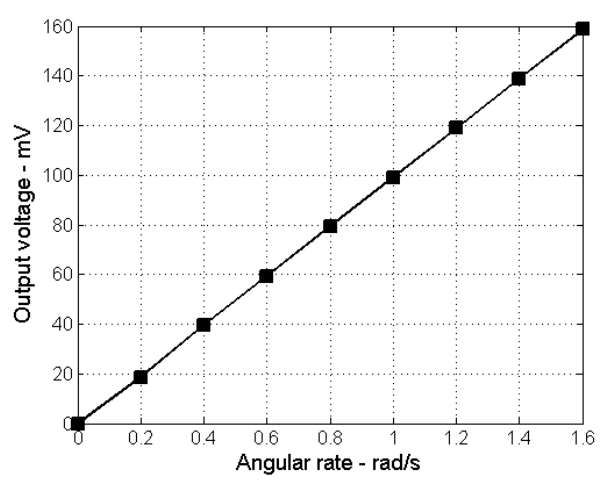

Fig. 12. Output voltage versus input angular rate 


\section{Conclusion}

In this paper, we have succeeded in designing a new structure of a MEMS - based vibratory micromachining gyroscope which exploits the electronics and mechanical cosimulation using finite element method. The proposed structure has a resonance frequency of $13324 \mathrm{~Hz}$ and the sensitivity of $100 \mathrm{mV} / \mathrm{rad} / \mathrm{s}$. Our work can be applied to design and simulate more complicated structures of gyroscopes like differential driving frame structure, tuning fork structure gyroscope, or high-order gyroscopes.

\section{References}

[1] Ayazi, Farrokh, and Khalil Najafi. "Design and fabrication of high-performance polysilicon vibrating ring gyroscope." Micro Electro Mechanical Systems, 1998. MEMS 98. Proceedings., The Eleventh Annual International Workshop on. IEEE, 1998.

[2] Maenaka, Kazusuke, et al. "Design, fabrication and operation of MEMS gimbal gyroscope." Sensors and Actuators A: Physical 121.1 (2005): 6-15.

[3] Sang Won Yoon, Sangwoo Lee, Khalil Najafi, Vibration-induced errors in MEMS tuning fork gyroscopes, Sensors and Actuators A: Physical (2012), pp. 32-44.

[4] Weinberg, Marc S., and Anthony Kourepenis. "Error sources in in-plane silicon tuning-fork MEMS gyroscopes." Microelectromechanical Systems, Journal of 15.3 (2006): 479-491.

[5] Liu, Guangjun, et al. "Effects of environmental temperature on the performance of a micromachined gyroscope." Microsystem Technologies 14.2 (2008): 199-204.

[6] Cenk Acar, Andrei Shkel. "MEMS Vibratory Gyroscopes: Structural Approaches to Improve Robustness". 2008. p. 8 section "1.5 Applications of MEMS Gyroscopes".

[7] D. Piyabongkarn, R. Rajamani, M. Greminger, The development of a MEMS gyroscope for absolute angle measurement, IEEE Transactions on Control Systems Technology 13 (2005), pp. 185-195.

[8] K. Liu, W. Zhang, W. Chen, K. Li, Fu. Dai, F. Cui, X. Wu, G. Ma, Q. Xiao, The development of microgyroscope technology, Journal of Micromechanics and Microengineering, vol 19, no 11 (2009).

[9] K. Shcheglov, DRG-A hight performance MEMS gyro, in Proc. Joint Precision Azimuth Sensing Symp., Las Vegas, NV, Aug. 2-4, 2010.

[10] M. W. Putty, A micromachined vibrating ring gyroscope, Ph.D dissertation, Univ. Michigan, Ann Arbor, MI, 1995.

[11] Alexander A. Trusovs, Adam R.Schofield, Andrei M. Shkel, Micromachined rate gyrocope architecture with ultra-high quality factor and improved mode ordering, Sensors and Actuators A: Physical 165 (2010), pp. 26-34.

[12] Alexander A. Trusovs, Igor P. Prikhodko, Sergei A. Zotov, Andrei M. Shkel, Low-Dissipation Silicon Tuning Fork Gyroscopes for Rate and Whole Angle Measurements, IEEE Sensors Journal, vol. 11, no. 11, November 2011, pp. 2763-2770.

[13] COMSOLMultiphysicsUsersGuide_4.3.pdf. http:// people.ee.ethz.ch/ fieldcom/pps-comsol/documents

[14] COMSOLMultiphysicsUsersGuide_4.4.pdf. http://www2.humusoft.cz/ftp/comsol/guides/ 